\title{
44. ORIGIN OF SEISMIC REFLECTORS WITHIN CARBONATE-RICH SEDIMENTS FROM NORTHEASTERN AUSTRALIAN MARGIN ${ }^{1}$
}

\author{
Richard D. Jarrard ${ }^{2}$ and Philip A. Symonds ${ }^{3}$
}

\begin{abstract}
We use continuous velocity records from 12 sites and continuous density records from 9 sites from Ocean Drilling Program (ODP) Leg 133 to examine both direct and indirect controls on seismic reflectors and depth-to-time conversion for the northeastern Australian margin. In these carbonate-rich sediments, the character of both velocity and density appears to be responding primarily to porosity variations and indirectly to lithologic or diagenetic variations. However, we find no consistent empirical relationship between velocity and porosity because of intrasite and intersite variations in style of cementation.

Impedance, the product of velocity and density, is dominated by porosity change throughout the depth range studied, but the mechanism of this control changes: porosity influence on density is an important impedance control in the top 100 meters below seafloor (mbsf), while porosity influence on velocity is most important to deeper impedance variations. This difference arises from the relative insensitivity of velocity to porosity change at the high porosities of the uppermost 50 to $100 \mathrm{mbsf}$. Because velocity dominates most impedance variations and because velocity and density are locally well correlated, density can be omitted entirely from the calculation of most ODP synthetic seismograms without adverse effects.

Depth-to-time conversion can be based either on matching a synthetic seismogram to the seismic section or on a plot of two-way time vs. depth. Synthetic seismogram character is sensitive not only to the character of velocity variations caused by changes in porosity and diagenesis, but also to wavelet uncertainties and impedance interference patterns. Plots of two-way time vs. depth for these carbonate-dominated sediments are remarkably similar down to $250 \mathrm{mbsf}$ and moderately predictable down to at least 450 mbsf.
\end{abstract}

\section{INTRODUCTION}

Time-to-depth and depth-to-time conversions are critical elements of Ocean Drilling Program (ODP) planning, operations, and drilling interpretations. Sites are chosen on the basis of seismic sections, and often target penetration depths are based on time-to-depth interpretation of seismic horizons. Many seismic reflectors are not major lithologic boundaries, so it may be difficult to evaluate whether drilling has reached a target horizon. Finally and most important, the synthesis of the wealth of drilling data at a site with the three-dimensional variability detected by seismic surveys requires accurate depth-totime conversion.

During ODP legs, velocity and density logs are routinely used for synthetic seismograms and depth-to-time conversion, but such logs are only available below $\sim 100 \mathrm{mbsf}$. In contrast, measurements of physical properties of core can be best in about the top $100 \mathrm{mbsf}$, where the advanced piston corer (APC) yields superior recovery and much less core disturbance than deeper cores obtairied with the extended core barrel or rotary core barrel. Thus, ODP has the potential for a more complete depth-to-time conversion and for quality control, based on comparison and merging of core and log data.

During Leg 133, a remarkable quantity of both velocity and density data were gathered. In addition to routine measurements of velocity and density on a record quantity of recovered core, 12 sites have velocity logs and nine sites have density logs. A companion paper (Jarrard et al., this volume) details editing and merging of core and $\log$ data that results in 12 merged velocity logs (Fig. 1) and 9 merged density logs (Fig. 2), with each log extending from the seafloor to within a few meters of the bottom of the hole.

\footnotetext{
${ }^{1}$ McKenzie, J.A., Davis, P.J., Palmer-Julson, A., et al., 1993. Proc. ODP, Sci. Results, 133: College Station, TX (Ocean Drilling Program).

${ }^{2}$ Lamont-Doherty Earth Observatory of Columbia University, Palisades, NY 10964 U.S.A. Present address: Department of Geology and Geophysics, University of Utah, Salt Lake City, UT 84112, U.S.A.

${ }^{3}$ Division of Marine Geosciences, Bureau of Mineral Resources, Geology and Geophysics, P.O. Box 378, Canberra City, ACT 2601, Australia.
}

Here, we use these merged logs to address a number of questions. How variable are seismic two-way times as a function of depth? How critical are core velocity measurements for determining such time/ depth relationships? Is density information essential for constructing reliable synthetic seismograms, or can they be based on velocities only? How often, on the northeastern Australian margin at least, are seismic reflectors caused by lithologic changes that are readily recognizable in cores? How often are seismic reflectors caused by interference patterns of many thin beds, by visually nondescript porosity changes, or by diagenetic horizons? To what extent does porosity control both density and velocity, and does velocity show a consistent relationship to porosity?

The answers to these questions have direct concern for the northeastern Australian margin and indirect implications for seismic/drilling syntheses in other regions, particularly regions in which the dominant lithologic component is pelagic carbonate.

\section{DEPTH-TO-TIME CONVERSION}

Each velocity log can be converted to a log of two-way time as a function of depth (Fig. 3). If Jarrard et al. (this volume) are correct in concluding that these velocity logs are reliable, then the primary uncertainty in the two-way-time logs is whether the sampled core and borehole log velocities are representative of the much larger-scale velocity structure seen by seismic profiling. For layered sediments (such as pelagic carbonates and mixed terrigenous and carbonate sediments), velocities at the borehole are likely to be representative. In contrast, reefs can exhibit substantial lateral variations in vugular porosity along dissolution pathways, resulting in local porosities at the borehole that differ from those that might be seen by either a nearby borehole or by a seismic wave. Fortunately, these occasional differences should not cause systematic bias to the velocity log, and the integrated traveltime log is relatively insensitive to short-wavelength velocity excursions.

Accuracy of the two-way-time plots was independently tested with a checkshot survey at Site 820 (Davies, McKenzie, Palmer-Julson, et al., 1991). The two-way seismic traveltime between the shallowest 


\section{$\begin{array}{llllll}\text { SITE } 812 \text { SITE } 814 & \text { SITE } 816 & \text { SITE } 822 & \text { SITE } 817 & \text { SITE } 823\end{array}$}
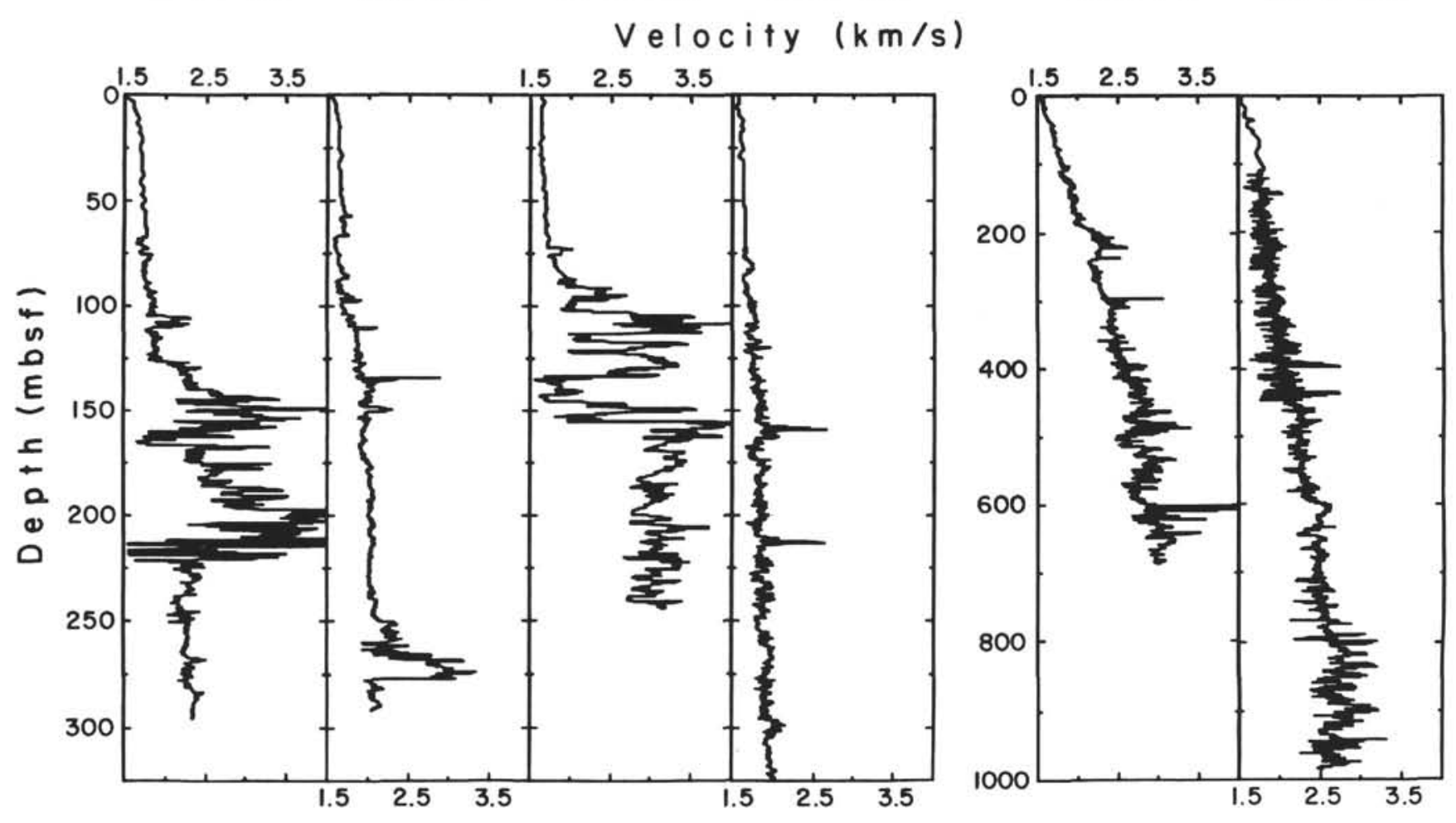

Figure 1. Best estimate of variations of velocity with depth at each site, based on merging of rebound-corrected core velocities with the velocity and pseudovelocity (from resistivity) $\log$ (Jarrard et al., this volume).

(93.8 mbsf) and deepest (334.6 mbsf) checkshots differs from the log-based time by $1.2 \mathrm{~ms}$, approximately the accuracy of individual checkshots and less than the width of a time/depth line in Figure 3.

The two-way-time curves of Figure 3 are similar in the top 150 mbsf and gradually diverge with greater depth, as the cumulative effects of intersite variations in cementation and lithology are felt. Clay mineral content has a strong impact on porosity and therefore velocity: the random orientations of newly deposited platy clay minerals cause very high porosities of 50\%-90\% near the seafloor. Mechanical compaction gradually reorients clay minerals to a more parallel orientation with very low porosity, but the porosity of clay rich sediments remains higher than that of sands and carbonates until the overburden is at least $0.5 \mathrm{~km}$ (Gregory et al., 1974; Hamilton, 1976). Correspondingly, presence of clays lowers the velocity of shallow sediments (e.g., Gregory et al., 1974; Hamilton, 1979), as is evident in the traveltimes of Figure 3. Clay minerals also lower velocity because their rigidity is much lower than that of quartz or carbonate. For example, Han et al. (1986) found that even a few percent clay is sufficient to substantially decrease the velocity of sandstones.

Hamilton (1979) presented empirical curves of two-way time as a function of depth for terrigenous and calcareous sediments. At 450 mbsf, he estimated a two-way time in pelagic carbonates of $475 \mathrm{~ms}$. For terrigenous sediments at the same depth, he estimated a two-way time of $520 \mathrm{~ms}$. In contrast, Carlson et al. (1986) used a different technique to develop a single empirical curve of two-way time vs. depth, which they inferred to be independent of lithology. For depths of $<0.5 \mathrm{~km}$, Carlson et al.'s (1986) curve is statistically indistinguishable from Hamilton's (1979) curve for terrigenous sediments. Site 815 , which is predominantly composed of clayey carbonates that are $60 \%-80 \%$ carbonate, has a two-way time at $450 \mathrm{mbsf}$ of $470 \mathrm{~ms}$, very similar to Hamilton's estimate of $475 \mathrm{~ms}$ for carbonates. Site 823 is much richer in clay and averages only about $50 \%$ carbonate; its two-way time of $490 \mathrm{~ms}$ is intermediate between Hamilton's (1979) pure carbonate and terrigenous curves.

Hamilton's empirical curves are based on deep-sea sediments in which mechanical compaction is the dominant mode of porosity reduction in the top $200 \mathrm{~m}$. For the pelagic carbonate sediments from Ontong Java Plateau considered by Hamilton (1979), diagenesis begins at about 150 mbsf and increases gradually with depth (Moberly et al., 1986). Schlanger and Douglas (1974) found a similar diagenetic pattern in other pelagic carbonates. In contrast, diagenesis is much more pervasive in Leg 133 carbonates. Velocity evidence for this diagenesis comes partly from the observation that two-way times of $430-440 \mathrm{~ms}$ at 450 mbsf at carbonate Sites 817 and 825 are $~ 10 \%$ less than Hamilton's values, while other carbonate sites are even faster (Fig. 3). Primarily, however, diagenesis is evident in both velocity and density logs as a profusion of mostly thin, very dense and fast beds (Figs. 1 and 2).

The dense and heterogeneous reef limestones of Sites 812 and 816 exhibit the most extreme departures of two-way time from the overall carbonate trend (Fig. 3). At both sites, the downward transition from pelagic carbonate to recrystallized reef carbonate occurs at such shallow depths that even by $200 \mathrm{mbsf}$ their two-way times are $25-40 \mathrm{~ms}$ less than times at the other 10 sites. Because the extent of reef diagenesis, and particularly post-diagenetic porosity, varies so dramatically from site to site (e.g., Figs. 1 and 2), the reefal carbonate time/depth curves from Sites 812 and 816 should not be used to estimate the time/depth curves that might apply at other, unlogged reef carbonate sites.

\section{SYNTHETIC SEISMOGRAMS}

Compared to time/depth curves, synthetic seismograms have both advantages and disadvantages as a means of linking site depth to seismic sections. Each synthetic seismogram uses the same velocity information as the time/depth curve, leading to identical time/depth 


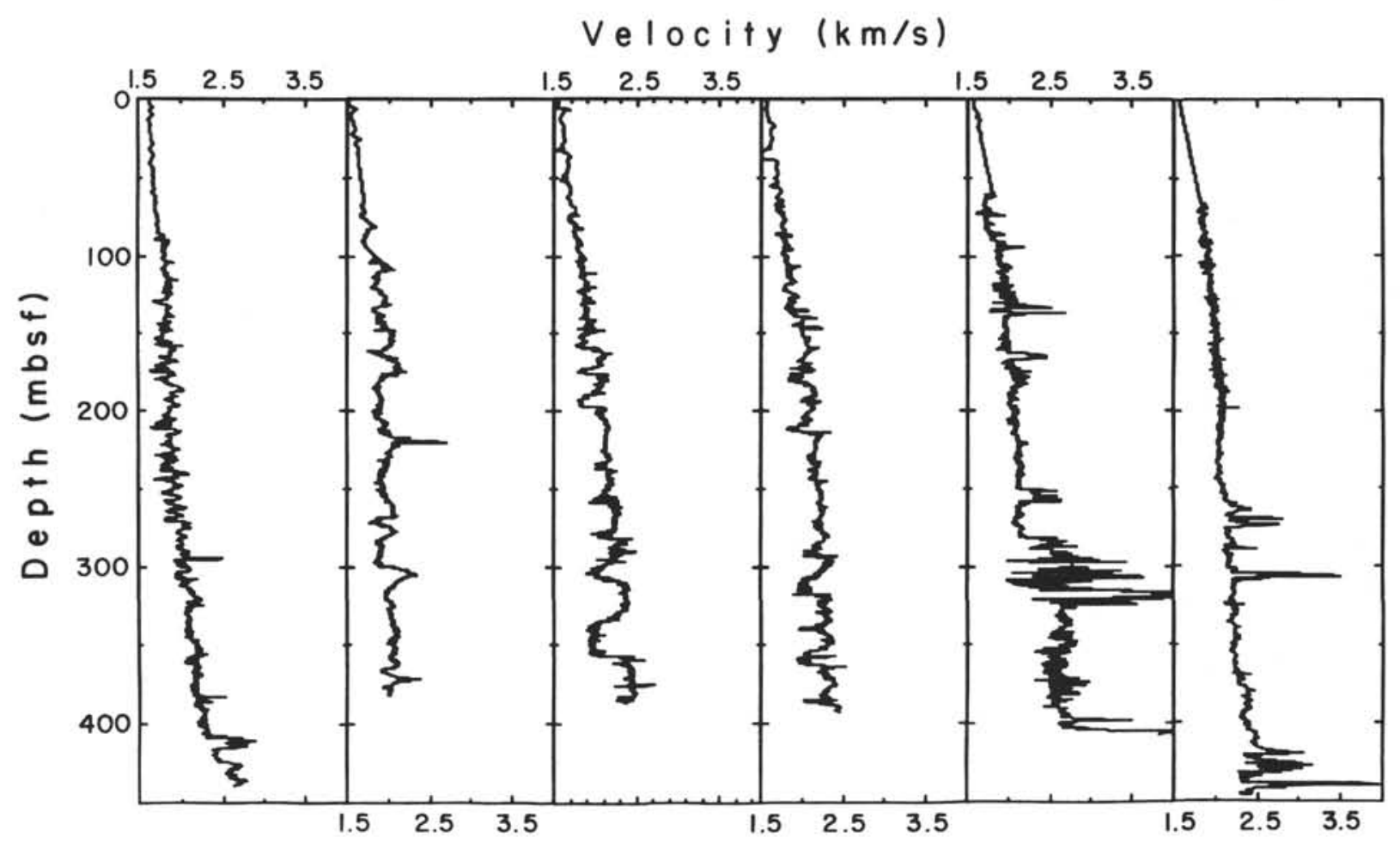

Figure 1 (continued).

results. However, the synthetic seismogram permits adjustment of this initial time/depth relationship, based on matching deep seismic reflectors with correlative peaks or troughs on the synthetic. At ODP, this advantage is most useful when some doubt exists about the accuracy of the velocity log or when, as in reef sediments or fractured rocks, the velocity log may not be representative of larger-scale velocities seen by seismic frequencies. In contrast, oil-industry drill holes are several times deeper than ODP sites, with the top 300-600 m usually unlogged, and no core velocities are available for the unlogged interval. Thus, industry finds synthetic seismograms to be more useful than time/depth curves.

Unlike synthetic seismograms, plots of two-way time vs. depth can be used with fair confidence to estimate time/depth relationships at unlogged or even undrilled sites, as long as one can reasonably infer that lithologies and diagenesis are broadly similar to those at a site where the time/depth curve is known. When such curves are available for various sites having different but known diagenesis and lithology, then the estimated effects of these two variables on plots of two-way time vs. depth can be used to refine estimates of expected curves for unlogged sites.

The primary disadvantage of synthetic seismograms is that they are degraded in their usefulness, and maybe even misleading, if the assumed wavelet is inaccurate or inappropriate or if the density log is inaccurate. Both potential inaccuracies are serious in the ODP environment. Academic seismic surveys commonly invest much less time and money into wavelet control and deconvolution than does the oil industry. Similarly, ODP logs shallower portions of holes, with less hole conditioning, than does the oil industry; consequently, many ODP density logs are of marginal quality.

During Leg 133, the shipboard party was fortunate to have very high-quality multichannel seismic data. These data are not deconvolved, so final comparison of synthetic and seismic cannot be degraded by uncertainties concerning deconvolution quality. Instead, we use an estimate of the BMR Rig Seismic wavelet for our synthet- ics. The source signature of this 80 -in. ${ }^{3}$ water gun has not been directly measured, but we estimated it by examining all site-survey seismic profiles, then selecting and averaging "clean" seafloor reflections from several regions. These reflections were chosen from areas where the reflection had a consistent form over many traces. We minimized biasing interference from shallow reflectors by selecting seafloor reflector patterns that persisted over widely spaced regions, in spite of very different lithologies and sedimentation rates.

Synthetic seismograms were calculated using a one-dimensional convolutional model, in which the BMR wavelet was convolved with an impedance $\log$ (velocity $\times$ density), sampled at 2 -ms spacing as a function of log-based two-way time. This convolutional model includes primaries plus interbed multiples, but it does not include seafloor/sea-surface multiples; the latter are present on seismic sections at traveltimes beneath the bottoms of the Leg 133 holes. The model also does not include spherical divergence or attenuation; thus, a $10 \%$ impedance increase creates the same-sized reflector at shallow depth as at great depth. In contrast, spherical divergence and attenuation do cause a gradual reduction in seismic reflector amplitude with increasing traveltime. However, the Leg 133 sites have such shallow penetration that seismic processing did not even need automatic gain control to augment amplitudes of deeper reflectors. Thus, spherical divergence and attenuation are not needed for the synthetic seismograms. Amplitudes of synthetic seismograms are scaled so that the largest peak on each has the same height.

The validity of the assumptions made in calculating synthetic seismograms is tested by the character match between synthetic seismograms and seismic sections. These comparisons are presented in companion papers (Feary et al., this volume; Symonds et al., this volume). In this paper the focus is not on individual seismic reflectors but on pervasive patterns among a large number of seismic reflectors. Therefore it is sufficient to analyze synthetic seismograms rather than seismic profiles. 


\section{Density $\left(\mathrm{g} / \mathrm{cm}^{3}\right)$}
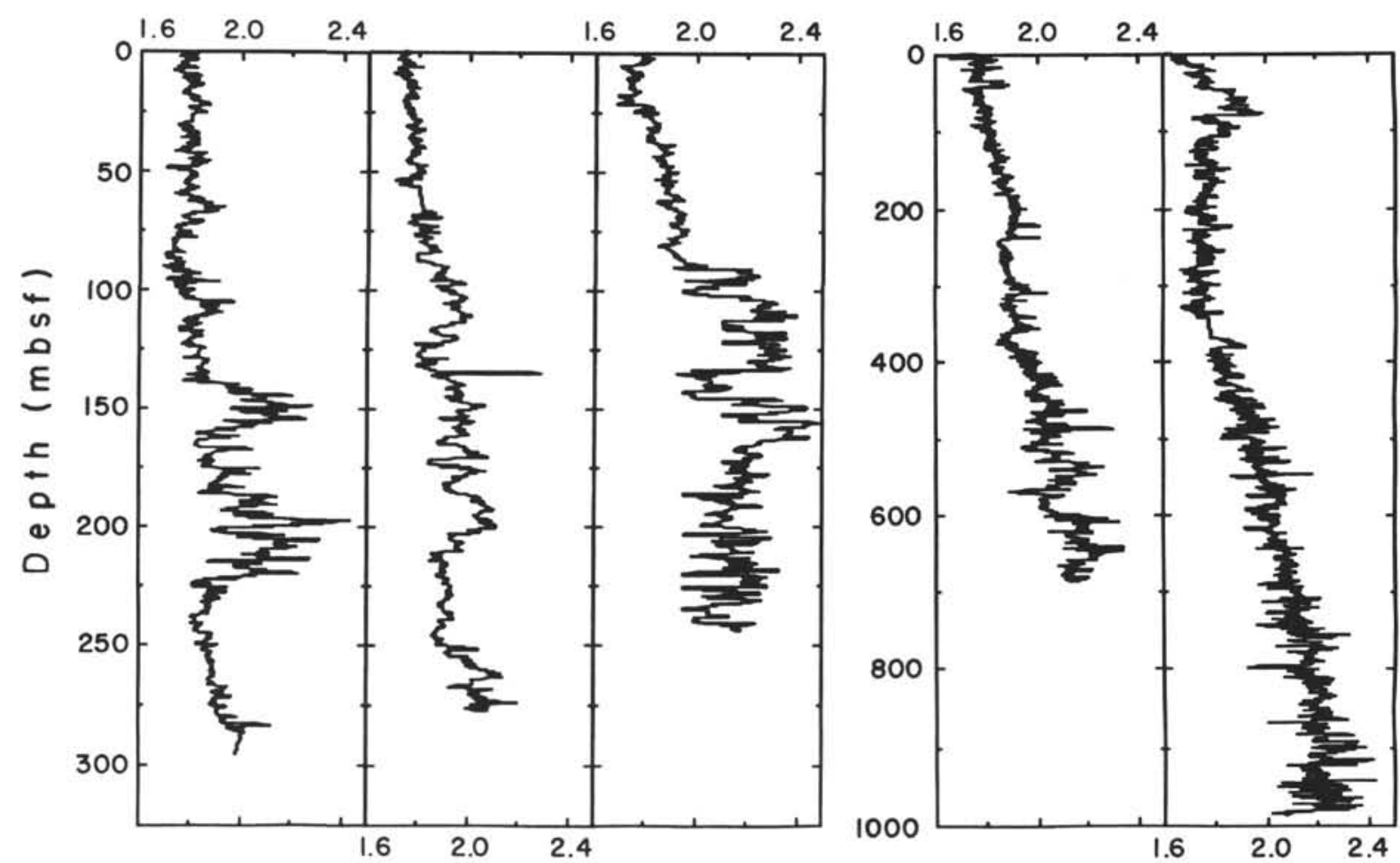

Figure 2. Best estimate of variations of bulk density with depth at each site, based on merging of edited GRAPE, index, density log, and pseudodensity (from resistivity) log measurements (Jarrard et al., this volume).

Although impedance is the product of velocity and density, it does not necessarily follow that a density log is required to produce a reliable synthetic seismogram. This is because reflection coefficients are proportional to the percentage of change in impedance. When velocity and density are highly correlated, the reflection coefficient patterns are nearly identical for a true impedance log and for an apparent impedance log based on the product of velocity and assumed constant density. Indeed, one can obtain a more accurate synthetic seismogram using a constant-density assumption than using the density log, if the density log has substantial erroneous patches, such as are caused by hole washouts.

To investigate the contribution of, and need for, density logs in Leg 133 synthetic seismograms, we calculated two synthetic seismograms for each site: one uses both sonic and density data, whereas the other assumes a constant density. Exceptions are Sites 822, 824, and 825 , which lacked density logs. These results are shown in Figure 4. Also shown in Figure 4 are the impedance logs as a function of two-way time, based on the product of velocity and either observed density or constant density. Each impedance log is normalized to the same total range in Figure 4 to facilitate comparison of the impedance character that creates synthetic seismogram reflectors.

At all sites, the two impedance logs shown in Figure 4 are nearly identical. Higher-resolution sampling of the impedance records (e.g., 1 instead of $2 \mathrm{~ms}$ ) should reveal more differences, but closer sampling would have virtually no effect on the synthetic seismograms, because the wavelet is so long $(60 \mathrm{~ms})$. Of course, the nearly identical impedance log pairs produce nearly identical pairs of synthetic seismograms (Fig. 4).

Rare differences between a pair of synthetic seismograms or between a pair of impedance logs serve as a focus for further analysis. Such differences may be caused by residual errors in the edited density $\log$, or they may indicate a horizon in which the usual pattern of density/velocity correlation has been perturbed by anomalous lithology or diagenesis.

A consistent pattern of differences between each pair of impedance logs is that the constant-density impedance log tends to have less character in the top 50-100 mbsf than does the impedance log using measured densities. The source of this observation is apparent in Figures 1 and 2: velocity exhibits little character in the top 50-100 mbsf, whereas for most sites, density character is as large in this shallow zone as at greater depth.

In part, this observation might be an artifact of the data used in Figures 1 and 2 . Above the start of in-situ logging, which is usually $\sim 60-70 \mathrm{mbsf}$, core data were used to determine density and velocity (Jarrard et al., this volume). GRAPE density records are continuous, whereas velocity data are discontinuous, and GRAPE noise level is probably higher than core-velocity noise level. The combination of these two measurement differences might give the illusion of higher variability for density than for velocity. However, the interval from 75 to $125 \mathrm{mbsf}$, which for almost every site is entirely based on in-situ log data, shows the same pattern of subdued velocity variations and relatively large density variations, compared to those deeper in the holes.

One can investigate depth-dependent variations in the relative contributions of velocity and density to impedance in another, more quantitative way. For $50-\mathrm{m}$ intervals at each site, we calculated the standard deviation $(\sigma)$ and mean $(\bar{x})$ of both velocity and density. We estimated the fraction of impedance variation due to velocity variation $\left(f l_{v}\right)$ as

$$
f l_{v}=\left(\sigma_{v} / \bar{x}_{v}\right)^{2} /\left[\left(\sigma_{v} / \bar{x}_{v}\right)^{2}+\left(\sigma_{d} / \bar{x}_{d}\right)^{2}\right],
$$

where the subscript $v$ refers to velocity and the subscript $d$ refers to density. The denominator used above differs from the denominator that more familiar propagation-of-errors analysis might suggest: $\left(\sigma i / \bar{x}_{i}\right)^{2}$, 
SITE $815 \quad$ SITE $819 \quad$ SITE $820 \quad$ SITE 821

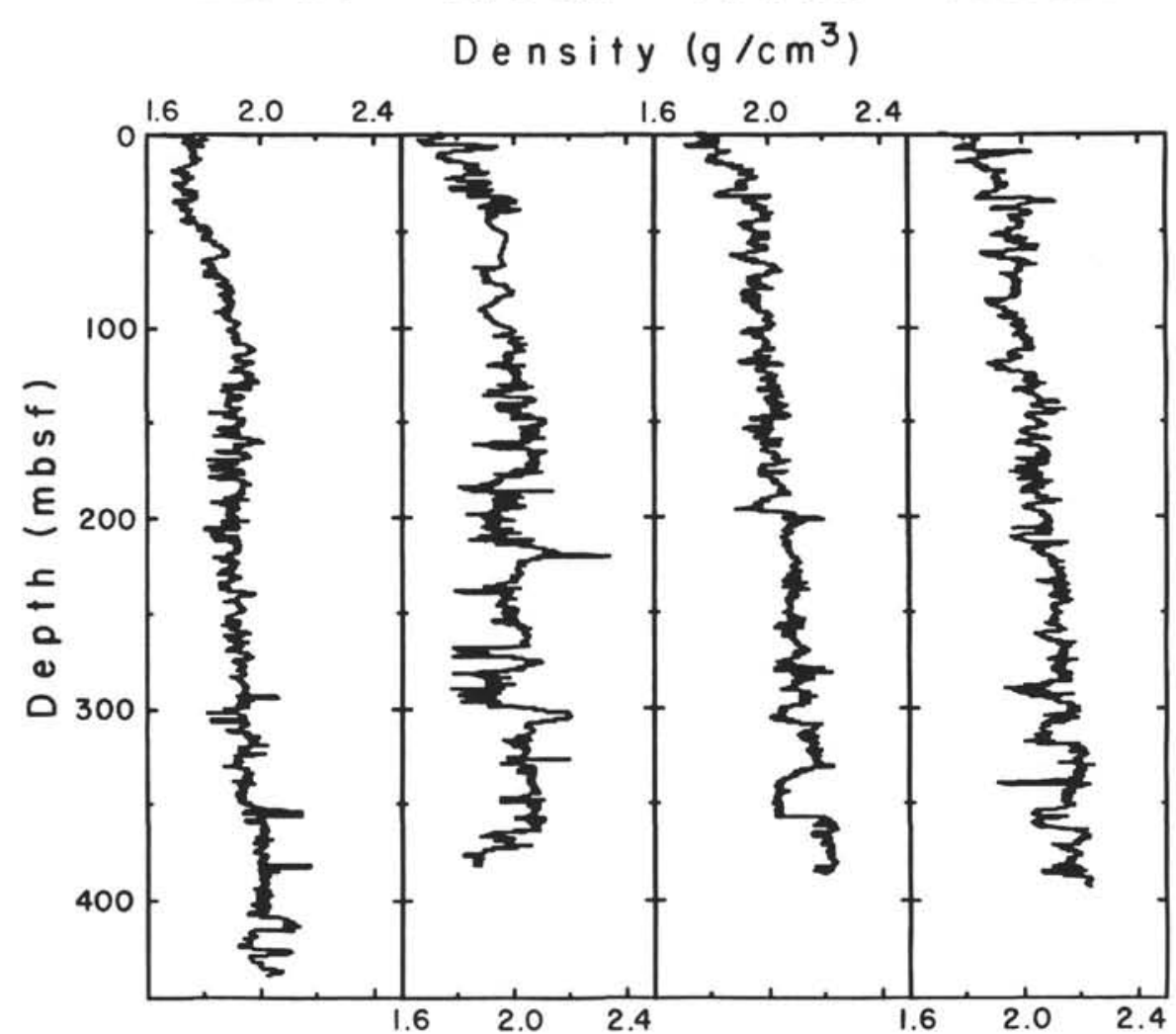

Figure 2 (continued).

Two-way time (ms)

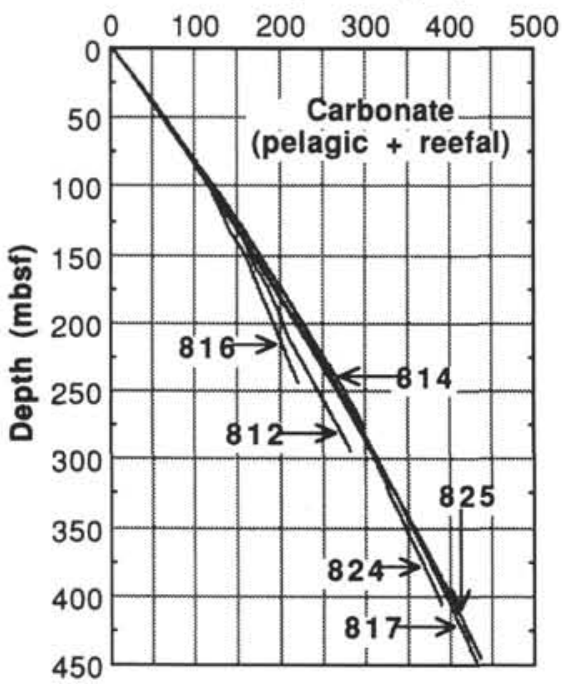

Two-way time (ms)

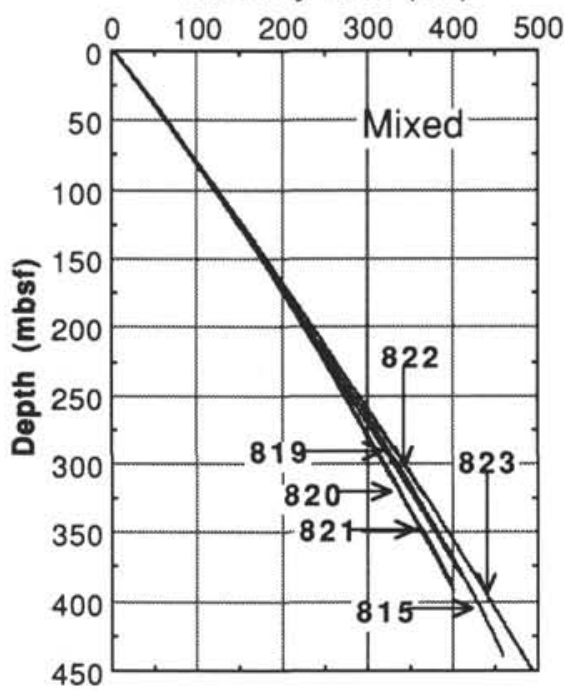

Two-way time (ms)

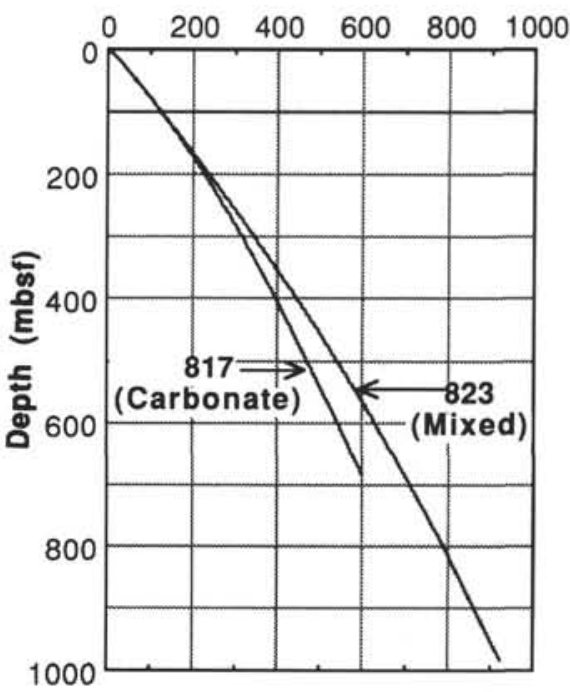

Figure 3. Variation of two-way time as a function of depth, based on merged velocity logs of Figure 1. "Mixed" sediments are a mix of pelagic carbonate and terrigenous components, usually primarily carbonate and secondarily clay minerals. Note that the plot at far right extends to greater depth and two-way time than do the other plots.

where $i$ indicates impedance. The reason for this difference is that velocity and density are not independent, and therefore velocity/density covariance increases the variance of impedance.

In Figure 5, the fraction of impedance variation resulting from velocity variation shows considerable intersite variation. Nevertheless, a pattern of rapid increase with depth is apparent. Below 100 mbsf, $65 \%-95 \%$ of the impedance variation is directly attributable to velocity variation, whereas density often dominates in the top 50 mbsf. Qualitative comparison of Figures 1 and 2 amplitudes might suggest that velocity and density variations would have similar impact on impedance below $100 \mathrm{mbsf}$. Reflection coefficients depend on the percentage of change in impedance, however, and these figures disguise the fact that percentage variation of velocity is much higher than percentage variation of density. 

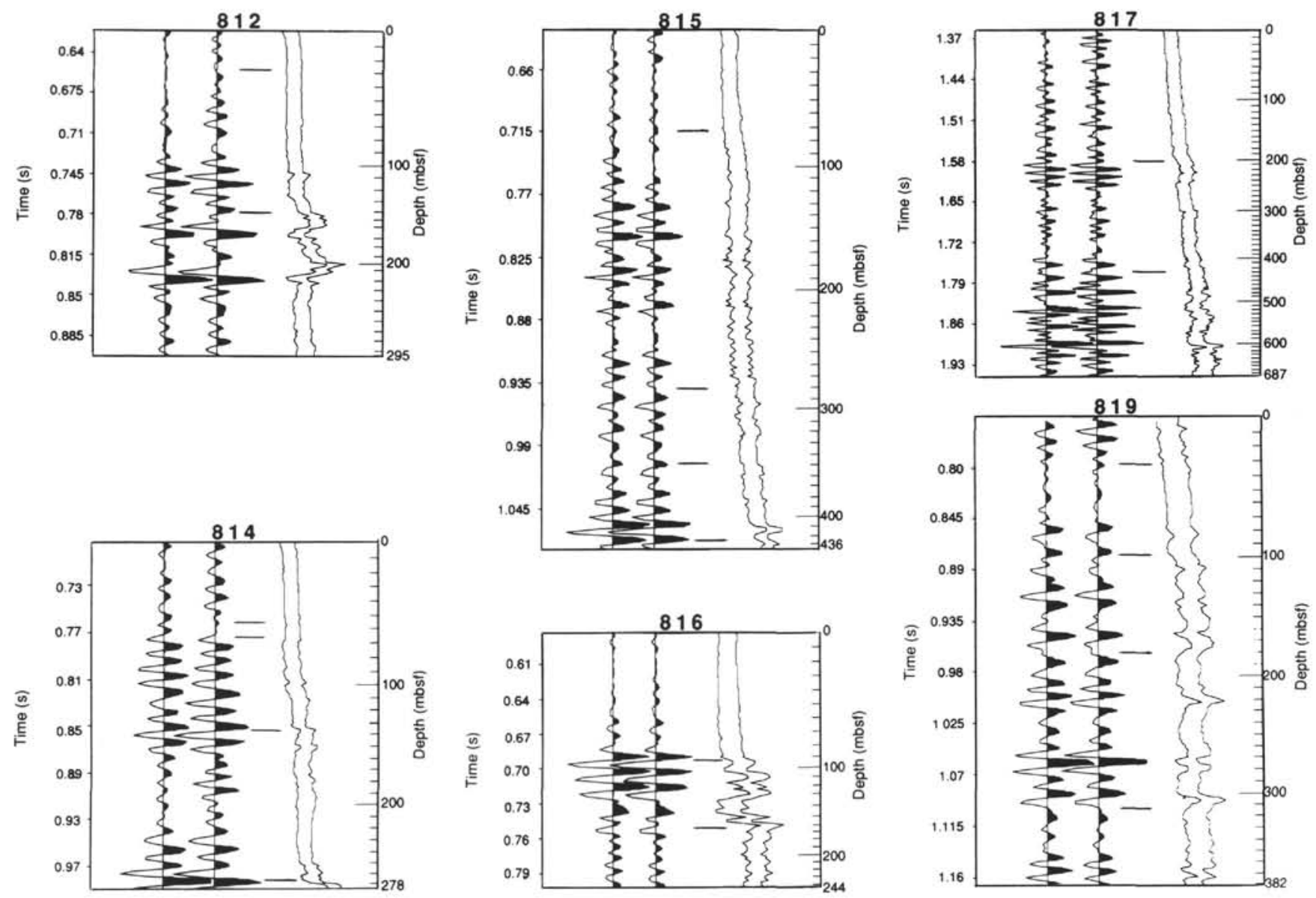

Figure 4. Synthetic seismograms and impedance logs for each site, plotted as a function of two-way time (left annotations) but with depth also shown (right annotations). Note that equal time spacing causes unequal depth spacing: depth ticks are farther apart in slow-velocity formations than in fast ones. Both synthetic seismograms and both impedance logs at each site use the same velocity log (Fig. 1). The left synthetic and the left impedance log in each pair assume a constant density, whereas the ones at right use the density $\log$ (Fig. 2). Three sites $(822,824$, and 825 ) are unpaired because they have no density log available. Each synthetic seismogram is amplitude-normalized to its largest peak or trough; each impedance log is amplitude-normalized to the total range of observed impedances. Short horizontal lines between synthetic seismograms and impedance logs denote the locations of lithostratigraphic boundaries (Davies, McKenzie, Palmer-Julson et al., 1991). All sites except Sites 817 and 823 have approximately the same scaling for the time axis; Sites 817 and 823 are so long that they use a time-axis scaling that is $50 \%$ of the others.

The pattern indicated in Figure 5 is consistent with our qualitative observation that excluding the density $\log$ from calculation of a synthetic seismogram has negligible effect, except in the top 50-100 mbsf. However, it differs in that velocity and density are specifically compared in Figure 5; in contrast, the synthetic seismogram pairs also include velocity/density covariation and, therefore, are even more similar than might be expected from Figure 5 alone.

To investigate further the depth-dependent difference between density and velocity contributions to synthetic seismograms, we must consider the primary variable that controls both velocity and density: porosity.

\section{RELATIONSHIP OF DENSITY TO POROSITY}

Bulk density $\left(\rho_{b}\right)$ is related to porosity $(\phi)$ by

$$
\rho_{b}=\phi \rho_{f}+(1-\phi) \rho_{m a},
$$

where $\rho_{f}$ is fluid density and $\phi_{m a}$ is matrix or grain density. For carbonate sediments, $\rho_{m a}=2.71$, and we assumed this grain density to transform all of the density records of Figure 2 to porosity. We note, however, that noncarbonate minerals (particularly clay minerals) make up $20 \%-50 \%$ of the mineral abundance in parts of Sites 815 and 819 through 823 . Consequently, some porosities at these sites are biased by several percentage points. A multilog simultaneous inversion for both porosity and mineralogy is potentially more accurate, but we have not undertaken such an inversion because its results would be very sensitive to variations in clay mineralogy.

\section{RELATIONSHIP OF VELOCITY TO POROSITY}

In contrast to straightforward density/porosity relationships, velocity/porosity relationships are subject to substantial uncertainty. For low-porosity rocks of a variety of mineralogies, the porosity/velocity relationship of Wyllie et al. (1956) has proven to be successful in the oil industry for almost half a century. Unfortunately, Wyllie's equation is reasonably accurate only for the generally low porosities of interest to the oil industry. For all porosities of $>\sim 25 \%$, this equation greatly overestimates porosities.

Wood (1941) simplified the theoretical Hookean elastic equations (e.g., Gassmann, 1951), by assuming that the rock medium lacks rigidity and thus both rigidity modulus and skeletal bulk modulus are zero. His resulting relationship between velocity and porosity predicts much lower velocities than does Wyllie's at a given porosity. At best, this relationship can be expected to be appropriate only at very high porosities (e.g., $>60 \%$ ). 

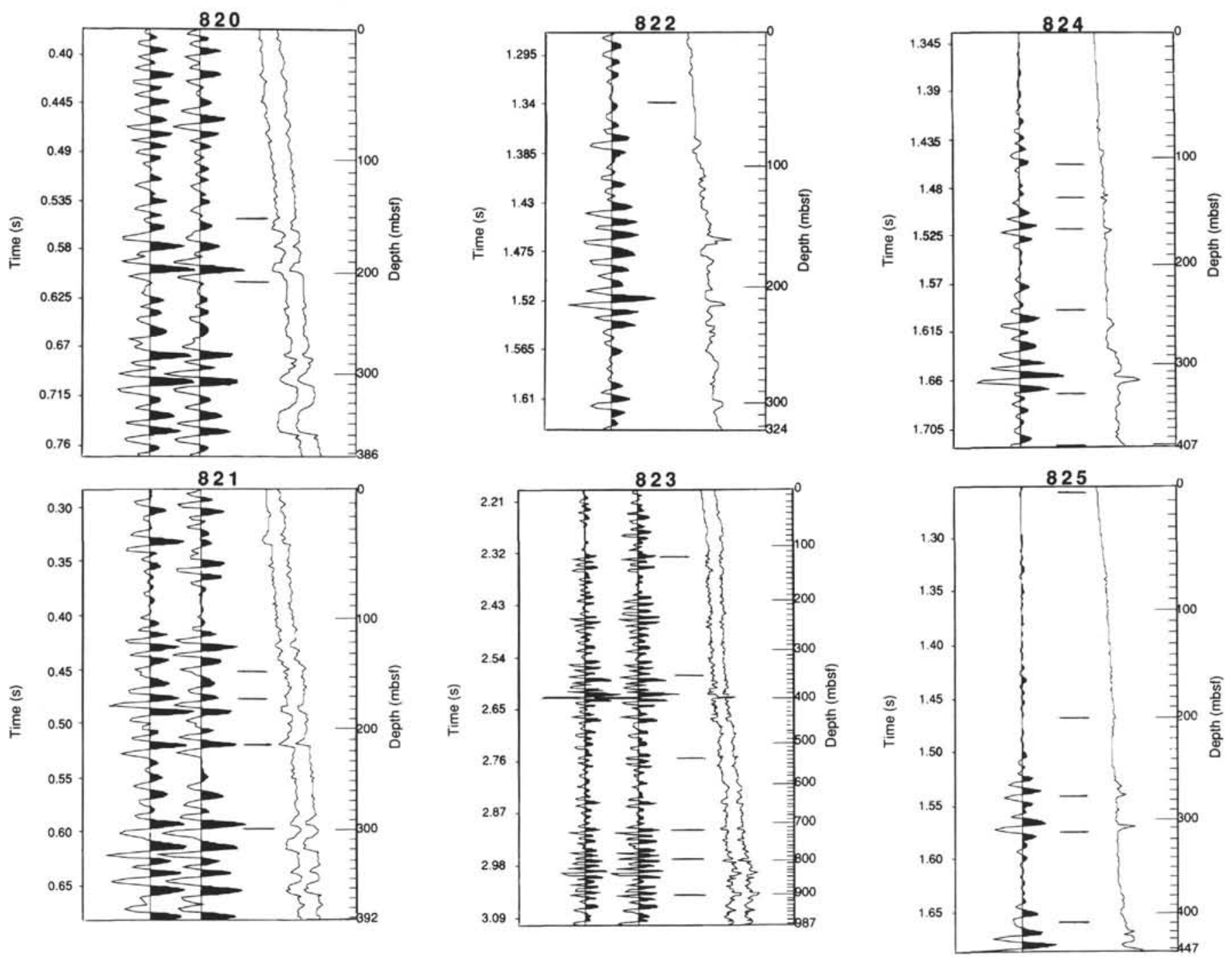

Figure 4 (continued).

Raymer et al. (1980) attempted to fill the gap between the lowporosity usefulness of the Wyllie et al. (1956) relationship and the possible very high-porosity usefulness of Wood's (1941) relationship. Unfortunately, Raymer et al. (1980) had only sparse data for porosities $>35 \%$. In our tests of the Raymer relationship using high-porosity data from ODP and the Deep Sea Drilling Program (DSDP), we found it to be a poor predictor (Jarrard et al., 1989; Fulthorpe et al., 1989). In contrast, Nobes (1989) found that a simple average of the Wyllie and Wood relationships was quite successful (e.g., Nobes et al., 1991), as follows:

$$
\Delta t=\phi \Delta t_{\text {Wood }}+(1-\phi) \Delta t_{\text {Wyllie }},
$$

where $\Delta t$ is traveltime (in $\mu \mathrm{s} / \mathrm{ft}$ ), which is related to velocity ( $V_{p}$ in $\mathrm{km} / \mathrm{s}$ ) by $V_{p}=304.8 / \Delta t$.

In Figure 6, plots are shown of velocity vs. porosity (derived from density as described above) for the 9 sites from Leg 133 that have reliable core and log data for both velocity and density. This figure shows that Leg 133 sites exhibit trends that are broadly similar, yet contain significant differences. These results concur with those of Urmos et al. (in press) that no single, comprehensive relationship exists between porosity and velocity, even within pelagic carbonate sediments. Urmos et al. (in press) found substantial differences in porosity/velocity relationships between Sites 803 and 807 on Ontong-
Java Plateau (Fig. 7). However, nearby Site 586 (Fulthorpe et al., 1989) did have a relationship similar to that at Site 807 (Fig. 7).

Of the published porosity/velocity relationships (Fig. 7), that of Nobes (1989) fits our data best for porosities of $>30 \%$, while that of Wyllie et al. (1956) is preferable for porosities of $<30 \%$.

Much of the intrasite and intersite velocity variation for a given porosity in Figure 6 may be attributable to varying styles of cementation. For example, a major change in cementation style at $164 \mathrm{mbsf}$ at Site 816 results in two separate porosity/velocity trends at this site. Jackson et al. (this volume) discuss in more detail the interactions of porosity and cementation for controlling the velocity and resistivity of Leg 133 sediments. Variations in proportion of clay minerals may also affect the porosity/velocity relationships, causing somewhat lower trends for Sites 815 and 819 through 823 than for the pure-carbonate Sites $812,814,816$, and 817 . The largest effect of clay content on velocity, however, is indirect and unseen in these plots: clay mineral content increases porosity through the inefficient packing of uncompacted clay particles.

In spite of the high intrasite and intersite variations in velocity as a function of porosity (demonstrated by Fig. 6), a systematic nonlinearity of trends is detectable. For porosities $>\sim 50 \%$, almost all sites show only a slow increase in velocity with decreasing porosity. In contrast, at porosities of $<50 \%$ velocity is much more sensitive to porosity, and possibly linearly so. Raymer et al. (1980) reached a 

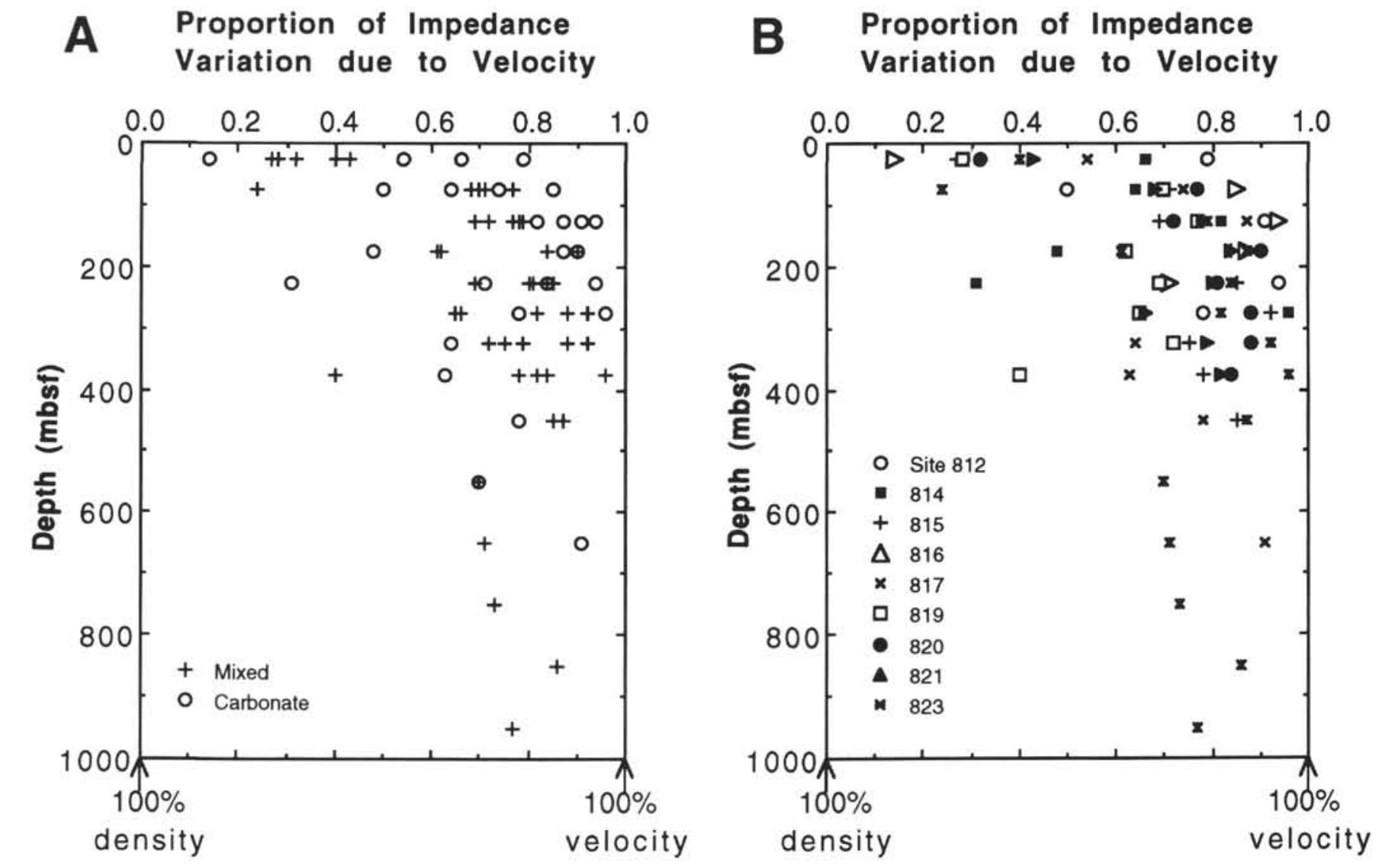

Figure 5. Variation with depth of the proportion of impedance variation that is caused by velocity; a value of zero implies that all impedance variation is caused by density variation. Note the rapid increase with depth, from a density dominance to velocity dominance. No systematic departures from this trend are seen among sites or among lithologies.

somewhat similar conclusion based on much less data: they estimated that velocity was exquisitely sensitive to porosity variations at $\sim 40 \%$ porosity, moderately sensitive below $40 \%$ porosity, and relatively insensitive above $40 \%$. Our observation is more consistent with that of Nobes (1989), who noted that low sensitivity of velocity to porosity is expected for fluid-supported high-porosity suspensions (e.g., Wood, 1941), and much more rapid variation of velocity with porosity change is expected for matrix-supported low-porosity rocks (e.g., Wyllie et al., 1956). Chen and Nur (1991) have used the concept of a critical porosity to model analogous sudden changes in other lithologies.

\section{ORIGIN OF SEISMIC REFLECTORS}

How closely is lithostratigraphy linked to seismic reflectors? If each lithologic change causes changes in either velocity or density, as seems plausible, then one might expect an associated seismic reflector, thereby permitting lateral extrapolation of observed downhole lithologic changes. The applicability of this approach, however, depends on two factors: wavelet resolution and lithologic dominance of impedance changes.

Lithologically induced impedance change can produce a simple seismic reflector only if it persists over a vertical distance of about one wavelength. For example, a $30-\mathrm{Hz}$ wavelet is capable of vertical resolution of only about $30 \mathrm{~m}$. An oil-industry rule of thumb is that the very highest vertical resolution achievable from seismic is about $1 / 8$ to $1 / 4$ wavelength and that even this is detected only as a subtle change in instantaneous frequency, rather than a complete seismic reflector.

We can use the synthetic seismograms of Figure 4 directly to examine the extent to which the 60 -ms-long BMR wavelet permits resolution of the many thin, isolated velocity spikes of Figure 1. However, caution is required because many of these spikes are diagenetically associated with impedance baseline shifts which do produce reflectors. For example, this is the origin of seismic reflectors associated with velocity spikes at $135 \mathrm{mbsf}$ at Site $814,160 \mathrm{mbsf}$ at Site 822, $100 \mathrm{mbsf}$ at Site 817, and $220 \mathrm{mbsf}$ at Site 819. Generalizing for this watergun wavelet, we observe that velocity spikes greater than about 1 to $2 \mathrm{~m}$ thick appear to affect the seismic reflection pattern.

Seismic resolution of a feature depends both on its own size (both amplitude and wavelength) and on proximity to other seismic reflectors. Depending on velocity, the 60 -ms BMR wavelet extends more than 50 to $90 \mathrm{~m}$. Yet examination of Figure 1 shows that large velocity changes commonly occur within much shorter distances. Thus, we can anticipate that many or most seismic reflectors will be interference patterns caused by multiple reflection coefficients, some constructively interfering and some destructively interfering. For example, the lowest portion of Site 820 has a fairly simple velocity structure (Fig. 1): three thick, boxcarlike layers (310-335 mbsf, 335-360 mbsf, and 360-390 mbsf) all different in velocity. Yet the seismic reflector pattern for this interval (Fig. 4) consists of five peaks that would be unlikely to be interpreted as the three interfaces (except with the hindsight of seeing side-by-side impedance and synthetic seismogram).

Lithologic dominance of impedance variations is often indirect: lithology changes do not affect matrix density and matrix velocity as much as they affect porosity. For example, Gulf Coast sands and shales produce seismic reflectors in this manner. Porosity changes can also occur without a triggering lithologic change, particularly in carbonate-dominated environments like the northeastern Australian margin, where diagenesis is pervasive. Either lithologic or porosity 

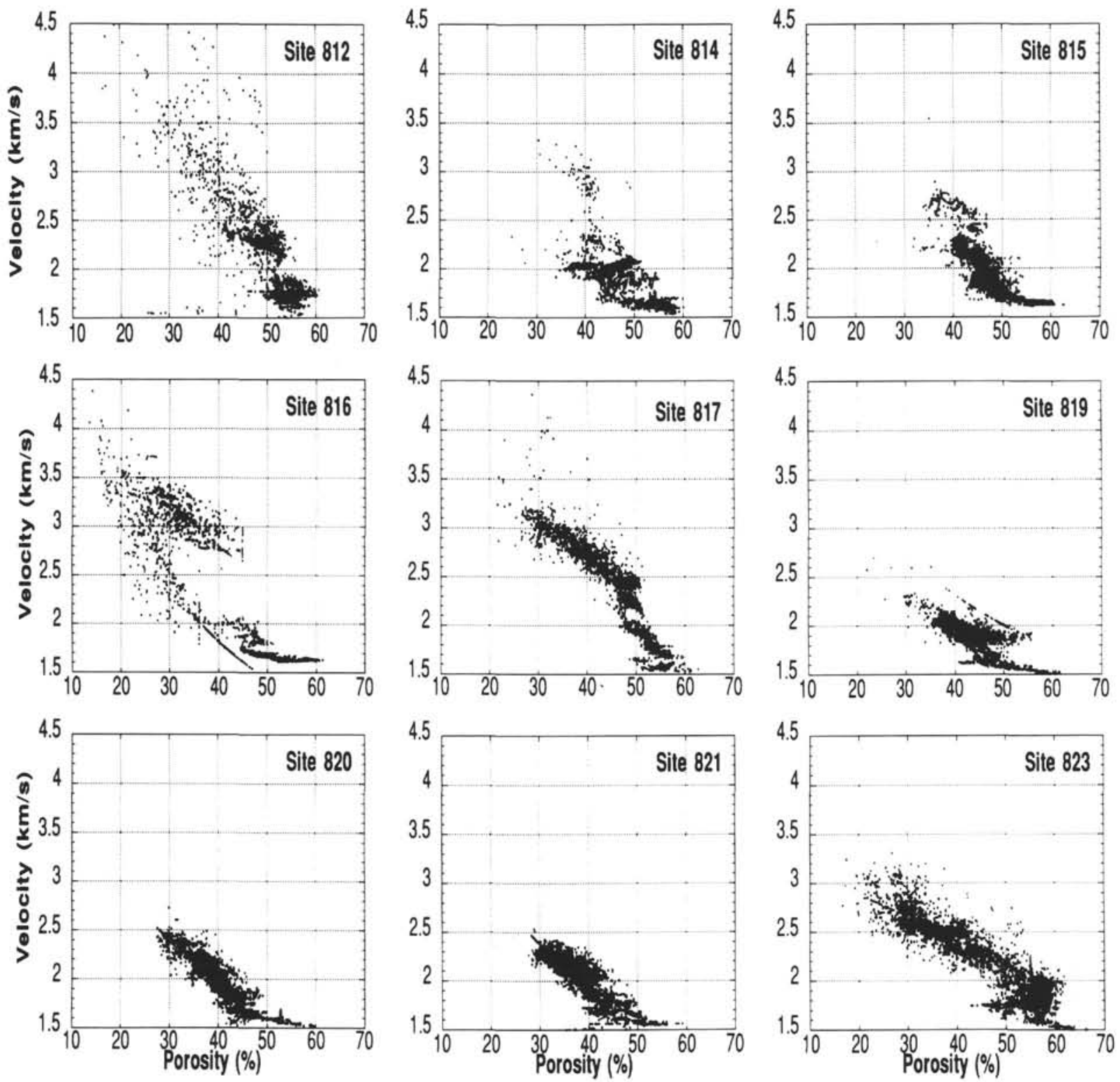

Figure 6. Crossplots of porosity (calculated from density) vs. velocity for all sites having both velocity and density records in Figures 1 and 2. Note the site-specific nature of velocity/porosity relationships, with sudden offsets attributable to diagenetic changes that affect velocity more than porosity. Note also that velocity is relatively insensitive to porosity for porosities of $>50 \%$.

changes may mark a major change in depositional facies or environment, but visual core description is much more likely to recognize lithologic rather than porosity changes. Thus, one wonders whether lithostratigraphic unit boundaries identified in ODP cores are likely to be associated with significant seismic reflectors.

Of the 44 lithostratigraphic unit boundaries defined by initial core descriptions (Davies, McKenzie, Palmer-Julson, et al., 1991) for the 12 sites of this study, 42 are within the depth intervals spanned by our merged logs of Figures 1 and 2. The positions of these unit boundaries are shown in Figure 4 by horizontal line segments between the synthetic seismograms and impedance logs. With such a display, one can examine whether or not each boundary is associated with a substantial impedance change (either increase or decrease), and whether it is marked by a seismic reflector that is large enough in comparison to intraunit reflectors to be distinctive.

Examining the impedance and seismic-reflector signatures of the unit boundaries in Figure 4 , we subjectively estimated that $\sim 18$ of the 42 boundaries, or $\sim 43 \%$, produced "significant" impedance changes.
Only 13 of the 42 boundaries, or $~ 31 \%$, are associated with substantial seismic reflectors; one quarter of those "matches" are coincidence, caused not by an impedance change at the unit boundary but by one well above the boundary. For example, of the two unit boundaries at Site 812 (Fig. 4), the upper one has neither an impedance change nor a reflector, while the lower one has a large impedance increase whose seismic manifestation has been obscured by the wavetrain from overlying reflectors. As another example, the large seismic peak marking the 339 -mbsf unit boundary at Site 824 is actually caused by impedance variations in the overlying interval from 310 to $328 \mathrm{mbsf}$.

Other investigators might reach somewhat different conclusions when evaluating the seismic impact of individual lithostratigraphic boundaries in Figure 4. Indeed, the identification of many lithologic changes in cores as lithostratigraphic boundaries is also subjective. Yet the conclusion seems inescapable that, at least in this carbonaterich marginal marine environment, seismic reflectors are more likely to arise from interference effects or from visually subtle porosity changes than from obvious lithostratigraphic boundaries in the cores. 


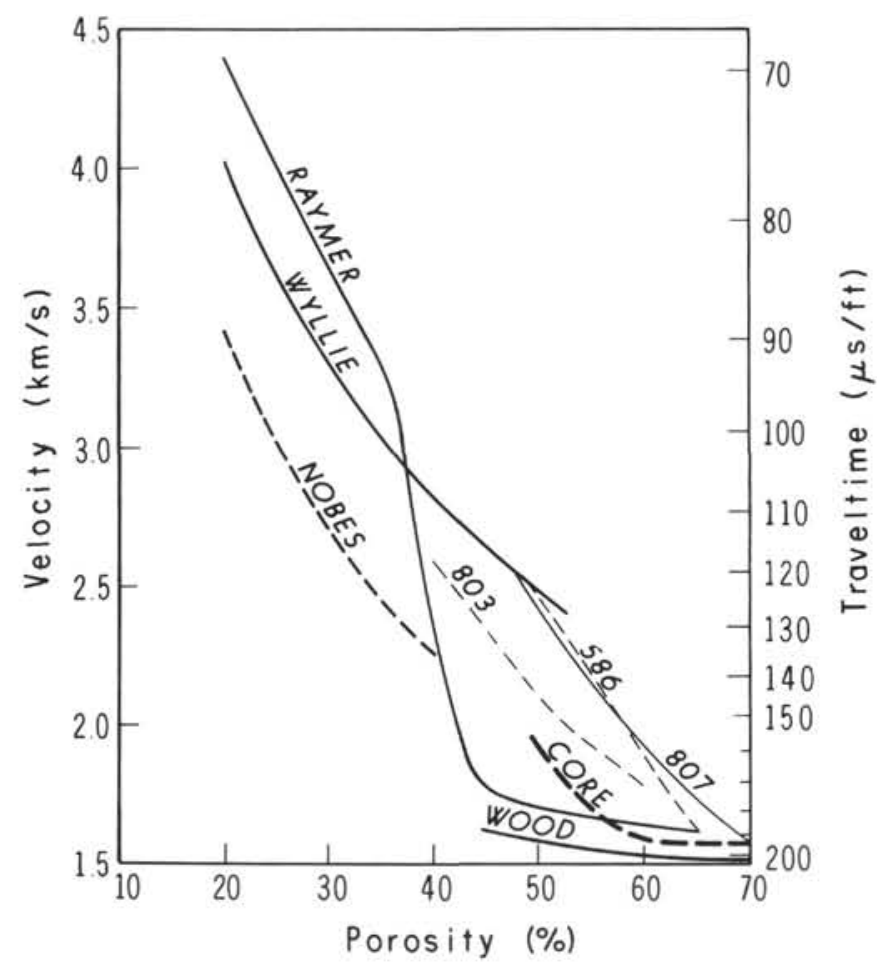

Figure 7. Crossplot of porosity vs, velocity for pelagic carbonates, shown with the same plot ranges as Figure 6 to compare data from other regions to those from Leg 133. Empirical and theoretical relationships shown are those of Wyllie et al. (1956), Wood (1941), Nobes (1989), and Raymer et al. (1980). Also shown are data from other pelagic carbonate sites: Site 586 (Fulthorpe et al., 1989), 803 (Urmos et al., 1992), and 807 (Urmos et al., 1992).

As an extreme example, at only $25 \%$ of these sites is the largest seismic peak or trough associated with a unit boundary.

Our analysis above has focussed on only one important relationship between lithostratigraphic units and seismic reflector patterns: the extent to which unit boundaries are marked by seismic reflectors. Although unit boundaries may not be readily correlated with reflectors, we observe substantial interunit variations in the abundance of reflectors; some units appear to be generally lacking in reflectors, while others have a preponderance (Fig. 4). Further, both coherence of reflectors and the geometry of reflector terminations are thought to be lithostratigraphically diagnostic (Vail et al., 1977).

Many of the seismic reflectors may have substantial diagenetic significance. We have inferred that the impedance pattern is controlled primarily by velocity (Fig. 4) and that velocity is controlled by both porosity and diagenetic style (Fig. 6). Schlanger and Douglas (1974) estimated that the porosity reduction of most pelagic carbonates was dominated by mechanical compaction above $\sim 200 \mathrm{mbsf}$, with diagenesis playing an increasingly important role at greater depths. In the near-reef sedimentary environments of Leg 133, velocity increases suggestive of diagenetic influence are apparent as shallow as 60 to $90 \mathrm{mbsf}$ (Fig. 1).

\section{CONCLUSIONS}

The 12 sites logged during Leg 133 have given us an opportunity to examine the heterogeneity of several relationships that impact the seismic manifestation of lithostratigraphic, porosity, and diagenetic changes. Both velocity and density exhibit dramatic short-wavelength variations as a function of depth, and both appear to be responding primarily to porosity variations and sometimes indirectly to lithologic variations. Cementation and diagenesis affect both velocity and den- sity through their impact on porosity, but cementation style affects only velocity, through its effect on frame modulus. Consequently, we found no consistent empirical relationship between velocity and porosity.

Density is sensitive to porosity variations throughout the observed range of porosities. In contrast, velocity is relatively insensitive to porosity changes at the high porosities of the uppermost 50-100 mbsf. Below this depth, velocity exhibits a larger percentage of change than does density for a given porosity change. Consequently, impedance (velocity $\times$ density) is dominated by porosity change throughout the depth range studied, but the mechanism of this control changes; i.e., porosity influence on density is an important impedance control in the top $100 \mathrm{mbsf}$, while porosity influence on velocity is most important to deeper impedance variations.

Depth-to-time conversion plots for these carbonate-dominated sediments (Fig. 3) are remarkably similar down to $250 \mathrm{mbsf}$. They can be estimated for a site with reasonable accuracy down to at least $450 \mathrm{mbsf}$, if one knows the approximate clay content and whether anomalously high diagenetic cementation is likely. In contrast, synthetic seismogram character is much less predictable, as the wavelet and interference patterns have large influences. Although impedance depends on both velocity and density, often the impedance log used in a synthetic seismogram can be based on the invalid assumption of constant density. Because sonic and density variations are strongly correlated and both variables respond to porosity, most density-induced impedance variations are already implicit in the sonic-induced impedance variations. Below $\sim 100$ mbsf, the two synthetics are usually similar, and where they differ, there is the chance that density log errors cause the density $\log$ to contribute more noise than signal.

\section{ACKNOWLEDGMENTS}

This study was supported by NSF Grant TAMRF No. 20539/ 20642 and by a grant from Atlantic Richfield Company.

\section{REFERENCES}

Carlson, R.L., Gangi, A.F., and Snow, K.R., 1986. Empirical reflection traveltime versus depth functions for the deep-sea sediment column. J. Geophys. Res., 91:8249-8266.

Chen, O., and Nur, A., 1991. Critical concentration models for the mechanical and acoustic properties of porous rocks and sediments. Eos, 72:438.

Davies, P.J., McKenzie, J.A., Palmer-Julson, A., et al., 1991. Proc. ODP, Init. Repts., 133: College Station, TX (Ocean Drilling Program).

Fulthorpe, C.S., Schlanger, S.O., and Jarrard, R.D., 1989. In situ acoustic properties of pelagic carbonate sediments on the Ontong Java Plateau. $J$. Geophys. Res., 94:4025-4032.

Gardner, G.H.F., Gardner, L.W., and Gregory, A.R., 1974. Formation velocity and density - the diagnostic basics for stratigraphic traps. Geophysics, 39:770-780.

Gassmann, F., 1951. Elastic waves through a packing of spheres. Geophysics, $16: 673-685$

Hamilton, E.L., 1976. Variations of density and porosity with depth in deep-sea sediments. J. Sediment. Petrol., 46:280-300.

1979. Sound velocity gradients in marine sediments. J. Acoust. Soc. Am., 65:909-922.

Han, D., Nur, A., and Morgan, D., 1986. Effects of porosity and clay content on wave velocities in sandstones. Geophysics, 51:2093-2107.

Jarrard, R.D., Dadey, K.A., and Busch, W.H., 1989. Velocity and density of sediments of Eirik Ridge, Labrador Sea: control by porosity and mineralogy. In Srivastava, S.P., Arthur, M.A., Clement, B., et al., Proc. ODP, Sci. Results, 105: College Station, TX (Ocean Drilling Program), 811-835.

Moberly, R., Schlanger, S.O., et al., 1986. Init. Repts. DSDP, 89: Washington (U.S. Govt. Printing Office).

Nobes, D.C., 1989. A test of a simple model of the acoustic velocity in marine sediments. J. Acoust. Soc. Am., 86:290-294.

\footnotetext{
- Abbreviations for names of organizations and publication titles in ODP reference lists follow the style given in Chemical Abstracts Service Source Index (published by American Chemical Society).
} 
Nobes, D.C., Mienert, J., and Dirksen, G.J., 1991. Lithologic control of physical-property interrelationships. In Ciesielski, P.F., Kristoffersen, Y., et al., Proc. ODP, Sci. Results, 114: College Station, TX (Ocean Drilling Program), 657-669.

Raymer, L.L., Hunt, E.R., and Gardner, J.S., 1980. An improved sonic transit time-to-porosity transform. Trans. SPWLA 21st Annu. Log. Symp., Pap. P.

Schlanger, S.O.., and Douglas, R.G., 1974. The pelagic ooze-chalk-limestone transition and its implication for marine stratigraphy, In Hsü, K.J., and Jenkyns, H.C. (Eds.), Pelagic Sediments: On Land and Under the Sea. Spec. Publ. Int. Assoc. Sedimentol., 1:117-148.

Urmos, J., Wilkens, R.H., Bassinot, F., Lyle, M., Marsters, J., and Mayer, L., in press. Laboratory and well-log velocity and density measurements from the Ontong Java Plateau: new in-situ corrections to laboratory data for pelagic carbonates. In Berger, W.H., Kroenke, L.W., Mayer, L.A., et al., Proc. ODP, Sci. Results, 130: College Station, TX (Ocean Drilling Program).
Vail, P.R., Mitchum, R.M., Jr., Todd, R.G., Widmier, J.M., Thompson, S., III, Sangree, J.B., Bubb, J.N., and Hatlelid, W.G., 1977. Seismic stratigraphy and global changes in sea level. In Payton, C.E. (Ed.), Seismic Stratigraphy-Applications to Hydrocarbon Exploration. AAPG. Mem., 26:49-221.

Wood, A.B., 1941. A Textbook of Sound: London (G.L. Bell).

Wyllie, M.R.J., Gregory, A.R., and Gardner, L.W., 1956. Elastic wave velocities in heterogeneous and porous media. Geophysics, 21:41-70.

Date of initial receipt: 12 April 1992

Date of acceptance: 13 September 1992

Ms 133SR-290 